\title{
A NEW VISION FOR EDUCATION IN QUALITY1
}

\author{
Robert Reinecke 2
}

\begin{abstract}
:
Excellezce in manufacturing follows immediately from the complementary attributes of productivity and quality. Both have a cuitural and technical component.

A culture of excellence in both doing the right thing and doing the thing right is a social phenomenon. Historically such a culture is often bred by difficult economic circumstances in a culturally and politically cohesive community. The history of South Africa is up to now was not successful in breeding competitive exellence in manufacturing. In fact our colonial but raw materials rich history inhibited demand and eventually development of excellence in this field.
\end{abstract}

The technical component of excellence in manufacturing is completely dependent on education. World trends in education is towards greater education of the whole population. Education today involves several different institutions and also the informal transfer of knowledge and skill.

This paper reviews the state of education in quality in South Africa. It offers the view that not only is more intensive and effective education necessary across the board but that a far greater emphasis should be placed on an effectively unified system of education as a whole with improved communication and co-ordination of effort.

\section{INTRODUCTION:}

In the final analysis, education in South Africa, in particular education in quality, is dependant on demand for skills by the community. Such demand depends on the current South African situation which is again related to the world situation. Therefor at this stage I want to introduce our vision for education in quality by making some observations regarding the state of the world, in relation to manufacturing.

\section{WORLD VIEW:}

iuccessful manufacturing world wide is being haracterised by greater development effort in be form of

* advanced design,

- better tools and equipment,

* improved manufacturing technology and doctrines.

his is being done in pursuing the manufacturig ideal of product

* conforming exactly to requirements,

* containing zero defects,

* made at a cost barely exceeding the cost of materials and energy and

- delivered reliably nearly instantaneously.

This ever increasing preparation effort is directly reflected in greater fixed cost of production. Especially in advanced electronic products it is very clear that the factory marginal cost approaches zero while the cumulative development cost becomes huge.

In all the world there is no defence, other than trade barriers and great transport costs, against a competitor expending significant resources in the pursuit of such manufacturing excellence.

In the second place we are looking at a manufacturing world where nations are surely combining into massive manufacturing blocks. The European Economic Community has triggered an American response in the form of economic agreement with Canada and Mexico. This block is actively courting South Africa and South America to join this such a union. This has already resulted in active discussion and negotiation between American and South African manufacturing industrialists and researchers culminating in the Foundation for Research and Development's Announcement of Opportunity in Manufacturing due to be released in November 1991.

The currently disjointed Far Eastern countries

I Paper read at the First SAQI National Quality Conference, storia, November 1991.

${ }^{2}$ Professor and Chairman of the Department of Industrial gineering, University of Stellenbosch, South Africa. 
$-15-$

is bound to respond to the increased economic threat of the European Economic Community and American economic aggregation policy in the long run. Mainland China is another dark horse in the more distant future.

It seems to me that a culture of quality (and productivity) really is based on a passive expectation to get and provide quality of product and service and an active drive to excel, to improve, to overcome and to compete successfully.

History shows that the world's great empires was built on the confidence engendered by success in undertakings. Building an empire was not only built on physical skills or a particular technology; more often it was built on the intangible education towards expectation of excellence and on the will and confidence to enforce such excellence. Today expressions like "British is Best", and "Made in Germany - of course", remain to remind us of the important quality conditioning applied to the minds of those successful people.

It is also interesting that very negative factors, such as the total destruction of German manufacturing resources during the 1940's and the agrarian position of Japan forced from isolation into the modern world earlier, bred a sucessful culture of quality, productivity and the competitive spirit.

It must be also observed that the development of of industrial engineering and its twin pillars of productivity and quality merged in a sense in the holistic approaches of Total Quality Control or World Class Manufacturing. Here the major advance was the integrated viewpoint but especially moving the human being into a central position in this striving towards excellence.

Where does all this leave South Africa? To answer that I investigate our manufacturing history.

\section{SOUTH AFRICAN QUALITY HISTORY:}

The historic pattern of technological development in South Africa during the last several decades however, did not include an industrial revolution and the painstaking stepwise implementation of discovered technologies in manufacturing. From about 1900, farming, mining and commerce dominated as careers in
South Africa. The professions followed, first teaching and religious study, professional agriculture, then professions like medicine, law and engineering; the latter some 50 years ago. The social development of the technological family in South Africa, excluding technical workmen, was therefore essentially top down.

Technology started with the maintenance and operation of mining equipment, progressed to maintenance and operation of some heavy industrial undertakings and then during WW II, to munition and other manufacturing under licence. Assembly of components made elsewhere, cars for example, was followed slowly by import substitution. The first world pattern of basic research, innovative design and manufacturing research, having a base in a substantial local demand leading to exports in time, only got underway with the arms embargo.

In this sense South Africa, for much of its early history, was technologically involved largely in licence agreements, assembly and import replacement; in short involved in imitation.

Such manufacturing, brightened by later extensive adaptation of design and especially manufacturing technology, to allow essentially first world products to be manufactured by means of a weird combination of first and third world inputs for a very, very small market, does not breed excellence in competitive international manufacturing.

It does, however, breed adaptability and the means to survive very unstructured manufacturing environments plagued by unreliable supply and quality of components. It also bred a nearly unique South African ability to produce low lot size runs successfully. This is a national strength still largely underrated and which can profitably be built on.

Engineering teaching came of age in South Africa during the period of international isolation leading enforced indigenous arms manufacturing and eventually excellence of product to internationally competitive standards. The fact that South Africa had actual combat experience with those weapons, was of course a help.

In more recent times the "Jacobs Report" [1] led to the initiatives of the National Productivity Institute and the SA Bureau of Standards. A far greater emphasis on quality resulted and eventually the South African Quality Institute was formed. This probably represents a key event in the manufacturing history of this country indicating a renewed determination 
towards excellence in manufacturing.

I have dwelled on the history of manufacturing in this country because that is so important in developing a vision of education and training in quality in this country.

\section{CURRENT STATE OF EDUCATION IN QUALITY:}

During $1990 \mathrm{I}$ investigated the state of the art in education in quality on behalf of the Advisory Committee on Quality chaired by Mr DC Luyt, of SA Bureau of Standards [2].

In summary it was found that material on quality does not seem to be taught at technical colleges at all. It is only the Pretoria Technikon where a special Higher Diploma in Quality exists. Thirteen technikons were found to teach at least a single subject in quality tools. For bachelor's degrees several universities teach a single quality subject while the University of Stellenbosch offers a degree in Industrial Engineering containing effectively four subjects in quality assurance, counting the big quality project as two subjects.

Graduate study is well provided for at Pretoria (after hours) and at Stellenbosch (winter/summer interupted course). The Stellenbosch course is especially aimed at mid-career rrofessionals wishing to progress to state of the irt technology and philosophy of quality.

Technikons may in general be well matched to he current demonstratable demand for quality echniques by industry but at least the philossphy of quality needs to be emphasised at echnical colleges as an ongoing thread through everal subjects and experiential training.

$\mathrm{n}$ terms of the perception of the broad public, :ven the perception of the community of nanufacturers, quality is still in many cases of econdary importance to meeting delivery dates nd target volumes; largely made difficult by abour problems. This attitude cannot last in he face of future economic depression in this ountry and the need to compete also internaionally. Therefor I turn to manufacturing rospects and education in the future South frica.

\section{THE FUTURE SOUTH AFRICA:}

I am now considering a scenario of an economy that will, in the medium term, deteriorate. That may either be accompanied by a strengthening resolve and confidence that economic and political difficulties can be overcome or by resignation and diminishing confidence. The latter case places South Africa on the slope to terminal third world status and is not considered further.

In the former case, that of a massive cultural orientation towards competitive manufacturing, immediate demands will be made on our education system for skilled and educated people with a culture of quality. The lead time of product from an educational system is long, much longer than the time needed to actually undergo training. In engineering we are now planning for skills which will only come to actual fruition in some 15 years time.

Our vision at Stellenbosch of university education in quality revolves around several key issues:

* Undergraduate emphasis in industrial engineering on quality to properly balance productivity.

- Graduate study to achieve excellence in creating state of the art quality assurance systems in undertaking where none exists.

- Co-operation in education and in R\&D with sister institutions.

\section{Undergraduate Education:}

Our undergraduate emphasis on quality now involves the following material:

Quality assurance management

Quality assurance objectives

Quality and reliability

Quality management

Quality System

Quality in marketing

Quality in production

Quality in verification

Quality and maintainability

Programmes for quality improvement

Quality Documentation and records

Reliability and testing

Quality and reliability in the field

Quality audits

Human factors

Quality cost

Product liability

Case studiesMethods and tools 
$-17-$

Collection and handling of data

Quality function deployment

tatistical tolerancing

Design of experiments

Statistical process control

Quality improvement by teamwork

Departmental analysis

System reliability

Launching a new product

Computer aided quality assurance

\section{Graduate Education:}

Graduate study at Stellenbosch involves a pioneering approach to advanced study in South Africa. The market is top technical people in mid career wishing to achieve exceptional skills in the design and management of quality and prepared to attend classes for three weeks at a time both winter and summer.

The course is designed firstly as a Master's degree programme; either as a Master degree in Engineering in the case of engineering graduates or as Master's degree in Engineering Science for science graduates. Non-graduates but who are quality assurance professionals, may follow any grotip of subjects not for degree purposes, up to all subjects forming part of the Diploma.

The course consists of five blocks of two subjects each. Blocks are presented during mid winter and mid summer and cover three weeks each. The planned student load per subject is 120 hours which includes pre-reading and homework. This gives a total of 1200 hours course work. The required thesis for the master's degree takes up another 1200 hours but may be completed at the student's workplace. Expert guidance will be provided for this activity. The course starts with three subjects covering general material, followed by three subjects of special theory. The last three subjects introduces various fundamental aspects of modern manufacturing technology and engineering. Further subjects include engineering economics and implementation. The course work is concluded with two special case studies; one presented by an overseas expert and the other by a local specialist.

Diploma students need to complete eight designated subjects for a total of 960 course hours plus 960 hours for a thesis.

\section{Co-operative Education:}

Finally, our vision of education in quality involves the concept of integrated education in training involving all tertiary educational institutions, industry and government building on fundamental education at school level. We see the following components of this notion:

* Identifying generic problems in manufacturing.

- Identifying state of the art R\&D work done in first world countries associated with such a particular problem.

* Forming co-operative bridges between the first world and South Africa's particular position as a second world industrially speaking. This could be done by integrating training and education of a student in both areas as has been successfully done at the university of Stellenbosch.

* Creating able and innovative teams consisting of factory, technikon and university representitives

* Designing an operating system for such a team to work in a complementary fashion to push the limits of South African excellenze forward. Such an operating system should recognise the skill of graduates to create solutions in principle, the skill of diplomates to implement prototype approaches in practice and the skill of people in actual practice to provide the breadth of background needed for a successful hard industrial application.

I believe that such an effort should be supported by excellence in preparing students for the future, hopefully successful South Africa. This could and should be done by communication between tertiary educational systems and including informal training to more clearly define the roles and functions of each so that every type of institution has a generally recognised "turf" which it can develop to its full extent in prosperous co-operation with other institutions.

\section{REFERENCES:}

1. "Verslag van die Komitee vir Ekonomiese Aangeleenthede van die Presidentsraad oor 'n Strategie en Aksieplan ter verbetering van Produktiwiteit in die RSA", PR 1/1989, Government Printer, 1990.

2. Reinecke R. "Verslag oor Stand van Opleiding in Gehalteversekering", Advisory Committee for Quality, 1990. Unpublished. 